\title{
Swedish Experience and Excellence in Wastewater Treatment Demonstrated Especially in Phosphorus Removal
}

\author{
Stig Morling \\ Sweco Environment AB, Stockholm, Sweden \\ Email: stig.morling@sweco.se
}

How to cite this paper: Morling, S. (2019) Swedish Experience and Excellence in Wastewater Treatment Demonstrated Especially in Phosphorus Removal. Journal of Water Resource and Protection, 11, 333-347. https://doi.org/10.4236/jwarp.2019.113019

Received: January 17, 2019

Accepted: March 17, 2019

Published: March 20, 2019

Copyright $\odot 2019$ by author(s) and Scientific Research Publishing Inc. This work is licensed under the Creative Commons Attribution International License (CC BY 4.0).

http://creativecommons.org/licenses/by/4.0/

\begin{abstract}
Water quality protection in Sweden has a more than 80-year history. The needed knowledge has by large been imported. Now, to some extent the development of phosphorus removal technology may be Swedish contribution to advanced knowledge. This paper presents the development in Sweden, mainly a close to 50-year period. Starting in the late 1960s, a standard of $<0.5 \mathrm{mg}$ P/l was the normally raised effluent criteria, regardless of the magnitude of the discharge flow. The successive sharpening of the discharge levels has today resulted in a level of 0.2 to $0.3 \mathrm{mg} \mathrm{P} / \mathrm{l}$ typically. As a matter of fact, even levels of 0.1 to $0.15 \mathrm{mg} \mathrm{P} / \mathrm{l}$ have been discussed. The period should a large extent demonstrated both improved technologies and a far better efficiency with respect to the use of chemicals and energy. Some important points in this development may be the understanding of the Oxygen Consumption Potential, as well as the identified needs for an improved nitrogen removal. Lately the problems of complex pollution agents and predominantly the remains of pharmaceutical agents have been identified. To illustrate the development during the 50-year period, two examples are presented from the Swedish context. The main conclusion in this paper is that the Swedish history on phosphorus removal illustrates how empirical science in practice sometimes works, including a never-ending need for an open mind and a readiness to take revised and improved knowledge on board.
\end{abstract}

\section{Keywords}

Waste Water Treatment, Phosphorus, Separation Techniques, Oxygen Consumption Potential, Nitrogen 


\section{Background}

What we call "modern wastewater treatment technology" could be said to have a short history. No more than a 100 to 150 -year time span has hosted an intense development of systematic ambitions to improve technologies in the waste water treatment field. This paper focuses on the following question: "What may be a Swedish Contribution and Excellence within wastewater treatment systems?" This document will try to give an answer to this question, especially by focusing on advanced phosphorus removal, as the issue has developed in Sweden during a 50-year period. The paper is divided into the following chapters:

Chapter 2 presents a short historic review with respect to the activities in the Swedish context on water protection.

Chapter 3 focuses on the development during the 1970s. This decade saw a very intense development of especially municipal wastewater treatment in Sweden. This chapter also focuses on some typical technological developments that may be a result of the phosphorus removal demands.

Chapter 4 points out some recent developments on water effluents demands as it may be identified, and valid for virtually all industrialized countries with dense population centres and needs of improved water protection.

\section{Short Historic Perspective}

In many respects, it may be correct to state that the modern water environment protection activities in Sweden started during the third and fourth decades of the $20^{\text {th }}$ century. A successive and improved insight of additional water protection needs, and implementation actions may be following a "20-year cycle".

The starting point in the early 1930s saw some primary treatment plants planned and successively built. A deepened insight that biological treatment was imperative for the protection of the receiving waters started to materialise in a broader scale during the 1950s. However, the start of a "true modern" water protection scheme could be dated around 1970. At that time the environmental concern focused on phosphorus as being by far the limiting factor for the Swedish water bodies. Once the environmental permits came into power the typical effluent stipulations were normally defined as follows:

$\mathrm{BOD}_{7}<15 \mathrm{mg} / \mathrm{l}$

Total $\mathrm{P}<0.5 \mathrm{mg} \mathrm{P} / \mathrm{l}$.

These permits were initially also given with specific, minimum percentage removal levels, typically $>90 \%$ both for BOD and $\mathrm{P}$ removal levels. This may be the starting point of a development of techniques to reduce especially phosphorus in the municipal wastewater discharge. The following chapter will present the technical development that to some extent represents a typical "Swedish contribution" to modern wastewater treatment. In this perspective it is important to keep in mind the overall European requirements on P-removal, as reflected in the, see Council Directive 91/271/EEC Concerning Urban Waste Water Treatment [1]. Often the accepted discharge values in a European perspective 
were found in the range 0.5 to $1.0 \mathrm{mg} \mathrm{P} / \mathrm{l}$.

\subsection{Technical Developments during the 1970s and 1980s}

An insight that the water pollution was caused not only by discharge of organics but also-at a far more severe way-by the uncontrolled discharge of nutrients, predominately phosphorus and nitrogen. The professor Halvard Oedegaard, Norwegian Technical University in Trondheim suggested during the 1980s a model to quantify impact of municipal discharges into the water bodies. The following relation was suggested:

$$
\mathrm{OCP}=1 * \mathrm{BOD}+4 * \mathrm{~N}+14 * \mathrm{~N}+100 * \mathrm{P}, \text { in } \mathrm{kg} \mathrm{O}_{2} / \mathrm{d} ;
$$

where:

$\mathrm{OCP}=$ Oxygen Consumption Potential, defined as $\mathrm{kg} \mathrm{O}_{2} / \mathrm{d}$;

$1 \times \mathrm{BOD}=$ Organic pollution, defined as $\mathrm{kg} \mathrm{O}_{2} / \mathrm{d}$;

$4 \times \mathrm{N}=$ primary oxygen consumption due to oxidation of ammonia nitrogen into nitrate nitrogen, defined as $\mathrm{kg} \mathrm{O}_{2} / \mathrm{d}$;

$14 \times \mathrm{N}=$ secondary oxygen consumption due to algae growth and decay driven by nitrogen, defined as $\mathrm{kg} \mathrm{O}_{2} / \mathrm{d}$;

$100 \times \mathrm{P}=$ secondary oxygen consumption due to algae growth and decay driven by phosphorus, defined as $\mathrm{kg} \mathrm{O}_{2} / \mathrm{d}$.

However, in Sweden the focus in late 1960s and early 1970s was on phosphorus discharge as the "limiting factor" for the receiving water bodies. The main "technological contributions" from the 1970s in municipal wastewater treatment development may be defined by three points:

1) The knowledge of chemical precipitation of phosphorous that developed successively;

2) The development of different separation models of the sludge;

3) The way to design and build the new wastewater treatment as "compact" plants.

\subsection{The Knowledge on Chemical Precipitation}

It is imperative to understand that the very strong focus on phosphorus removal meant a challenge for the Swedish water industry. The initial technological model was by far the so called "post-precipitation". This model was arranged as a separate treatment unit, downstream either primary sedimentation (and then called "direct precipitation") or following the main biological treatment (normally built as an activated sludge plant) and then called the post-precipitation. The initial solution for post-precipitation was to "blue print" the technology used for making potable water from surface water sources. This model follows three steps:

1) Injection and mixing of the precipitation agent;

2) The "build up" of the chemical floc by a successive flocculation by means of slow speed stirring;

3) The final separation of the chemical floc by different techniques. 
Typical performance results from a "classic" plant those years, based on biological treatment and post-precipitation were as follows:

$\mathrm{BOD}_{7}<10 \mathrm{mg} / \mathrm{l}$

Total $\mathrm{P}<0.3 \mathrm{mg} \mathrm{P} / \mathrm{l}$.

Please observe that the formal effluent standards were somewhat less stringent-see previous chapter!

As time went by during the 1970s, the improved process knowledge and investment concerns resulted in the development of different precipitation models. These variants were (initially) accepted with some reluctance by the environmental authorities. Two of these alternative models became for a time very attractive:

- The so-called pre-precipitation, and

- The simultaneous precipitation.

The pre-precipitation was used at plants including a primary sedimentation stage. The chemical agent (normally alum or ferric salt) was injected into the sand trap facility, enabling good mixing conditions and thus located upstream the primary sedimentation tanks. Thanks to the abundance of suspended matters in the raw waste water, a good flocculation occurred. A "phosphorus rich" primary sludge was thus removed from the primary sedimentation stage.

The simultaneous precipitation was developed partly thanks to the availability of a low-cost ferric product $\left(\mathrm{FeSO}_{4}\right)$, a refuse product from steel mills. This model may be a way of re-using a refuse compound. The salt was injected directly at the end part of the aeration basin in the activated sludge plant. An alternative model was developed in the Czech Republic by the addition of ferric salt into the return activated sludge stream. A further development of the simultaneous precipitation was introduced in the Swedish market during the 1990s, as the model was integrated into the SBR-system (Sequencing Batch Reactor), see Morling (2001) [2].

The chemical precipitation was also combined with modern versions of trickling filters. This configuration model was normally elaborated as a post-precipitation stage. The chemical stage followed directly after the trickling filter and a "combined" separation was used for the mixed biological and chemical sludge.

This development of different chemical precipitation models supported an improved process knowledge, enabling designers and operators to enhance the process efficiency. This knowledge also included a (needed) deeper understanding of the sludge handling system at the plants.

The chemical precipitation was initially based on three different agents:

- Alum sulphate or chloride;

- Ferric salts, both $\mathrm{Fe}^{2+}$, as ferric sulphate, and $\mathrm{Fe}^{3+}$, both ferric sulphate and ferric chloride and

- Lime products, initially both $\mathrm{CaO}$ and $\mathrm{Ca}(\mathrm{OH})_{2}$.

Rather soon, however, the "acidic" agents became the dominant agents in the market. The use of lime became less popular due to some important reasons. First, the needed dosage was substantially higher than those for alum and ferric 
salts. This in turn resulted also in higher amounts of sludge to dewater and deposit. An additional limiting factor was that the discharge $\mathrm{pH}$ in the treated water often was $>11$. This in turn represents sometimes a negative circumstance with respect to the receiving water body. When the $\mathrm{pH}$ value is high, the balance between ammonium ion and free ammonia is changed, and the higher $\mathrm{pH}$ means a larger part is free ammonia in the water. The increased amounts of free ammonia may represent an environmental threat for sensitive water bodies.

\subsection{The Development of Different Separation Technologies}

Especially the post precipitation model initiated a competitive development of different separation technologies in Sweden. Apart from the conventional clarifiers, either shallow basins (water depth around $2 \mathrm{~m}$ ) and "vertical flow" models (water depth around $4 \mathrm{~m}$ ), other more compact models emerged. It should be underlined that all these technologies have "roots" in the international water industry. The Swedish "contribution" has often been to take the different technologies on board and further develop and adopt them into the local environment.

Lamella settlers were simultaneously developed at Chalmers Technical University in Gothenburg (CIT), by the Research and Development Institute in the Johnson Group (AJFO) and at VBB, the leading consultancy group at the time (now a part of Sweco). A typical example of a lamella settling facility is presented in Figure 1.

Dissolved air flotation (DAF) separation model that was originally used in the paper industry was developed in Sweden by two engineering companies, $\mathrm{Pu}$ rac and Flotec. A typical flow sheet including the DAF is shown in Figure 2.

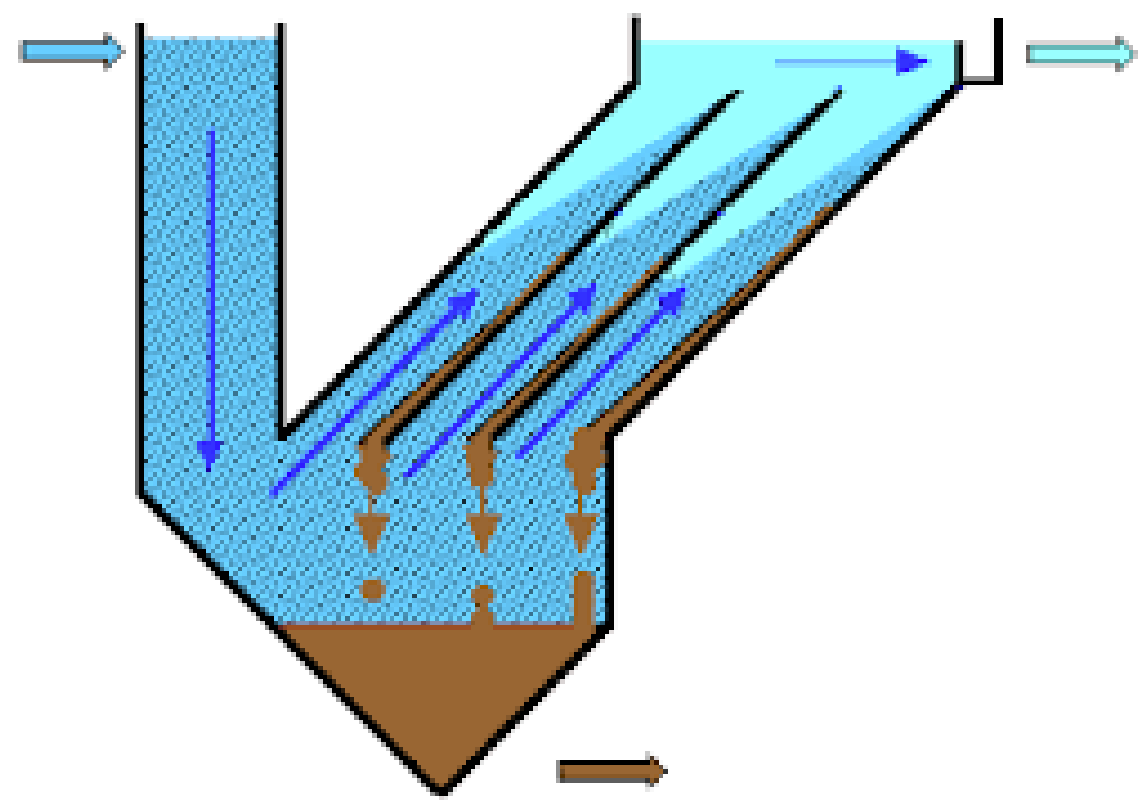

Figure 1. A typical lamella sedimentation function model (source: Nordic Water Products). 
The continuous sand filter called the Dyna Sand filter was developed within the research and development institute in the Johnson Group. In Figure 3 a typical sand filter construction is shown.

Later, the Drum Filter and Disc Filter were developed by inter alia Hydro Tech and Nordic Water Products. Accordingly, we find several disc filters developed in the international market, all with the potential to serve as a polishing separation stage at a modern wastewater treatment plant. Figure 4 shows a typical disc filter found on the market, developed by a Swiss and US company, later under the brand name of Aqua Aerobics.

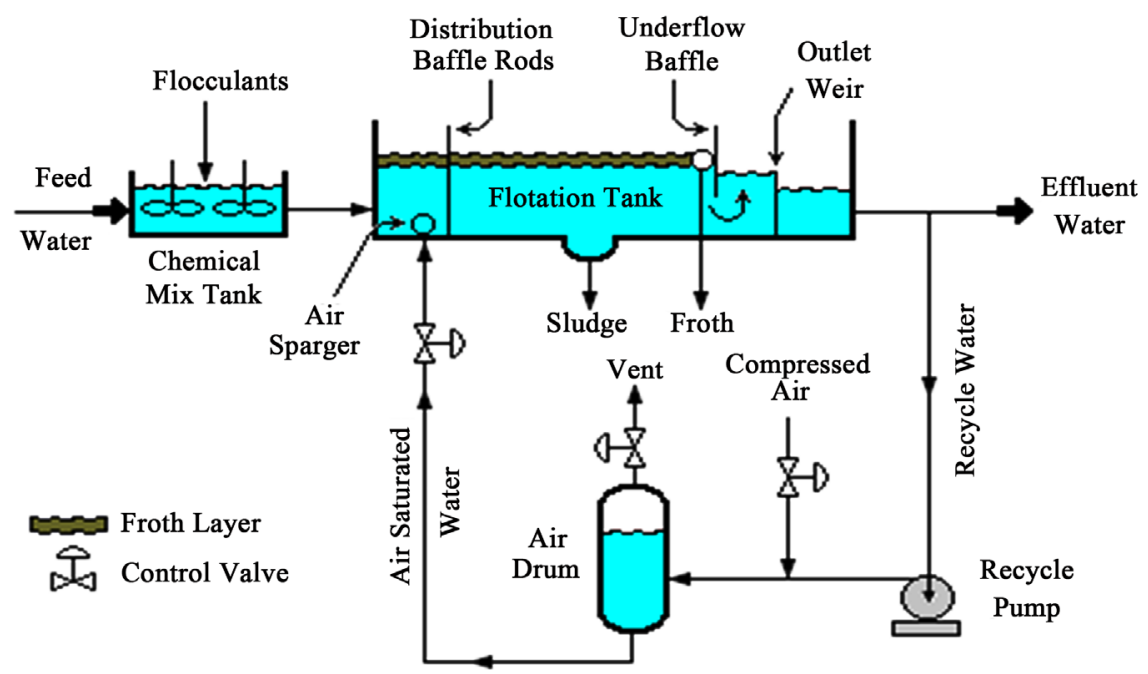

Figure 2. A typical flow scheme for wastewater based on dissolved air flotation.

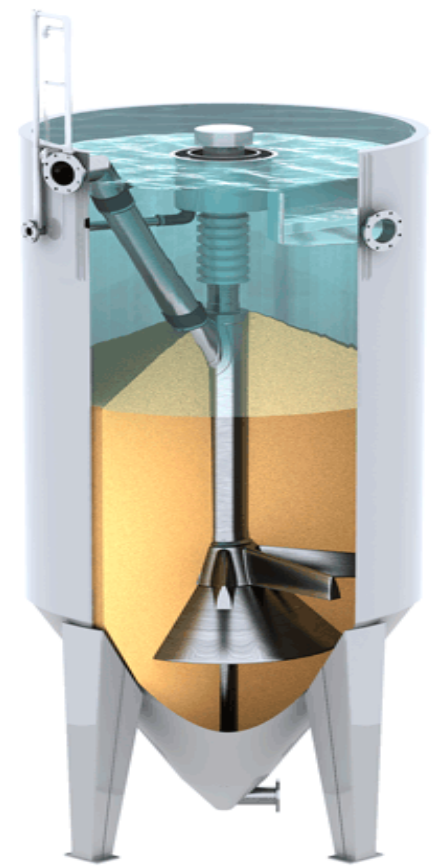

Figure 3. A standard unit for continuous sand filtration, as developed by the Johnson Group in Sweden (now in Nordic Water Products). 


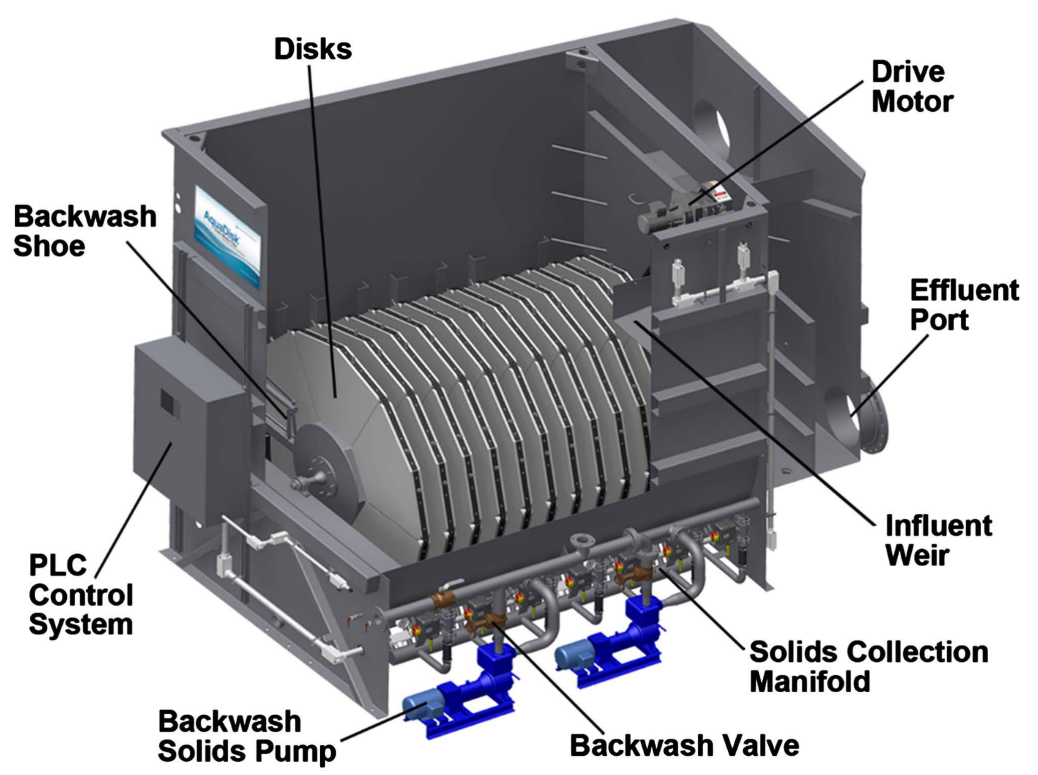

Figure 4. A typical disc filter unit found in the market for final separation of solids (Source: Aqua Aerobic Systems, Inc. Rockford, US).

All these separate techniques have not only survived but also developed into important parts of a modern treatment chain in a WWTP.

\section{The way to Design and Build Modern Wastewater Treatment Plants}

The very intense construction period in the 1970s saw a strong participation of turn-key contractors. One competitive pre-requisite was to find rational and area-saving design models ("small footprint" plants). Other conditions that promoted the compact plant were the prevailing climatic conditions in Sweden with cold and often snow-rich winters. This in turn called for "indoor" plants. The specific conditions that were the pre-requisite for the indoor plant have accordingly created important "side effect" knowledge within plant design and construction. This knowledge was related to demands for better indoor environment with respect to odours, humidity, corrosion and not least important, the aspects of work safety.

The compact model has as a matter of fact often resulted in a concept that may be called a "built in flexibility and upgrade potential" of the wastewater treatment facilities.

The requirements on effluent standards for treated wastewater virtually always include very low permissible levels with respect to BOD. However, this specific condition has been disputed for small and modest sized plants. In a doctoral thesis, Hey (2016) [3], regarding primary precipitation in conjunction with a fine grade drum filter (sieve openings from 40 to $100 \mu$ ) has been presented as one option. A second option was accordingly studied: fine grade screening and treatment in reversed osmosis. The latter model is not further commented here. The model based on pre-precipitation and fine grade screening is presented as a 
viable alternative especially for small and modest sized plants $(<10,000 \mathrm{pe})$. The model demonstrated improved efficiency with respect to P-removal, as well as lower energy consumption, especially in comparison with activated sludge plants. From the thesis, it is worth to quote some interesting conclusions:

"Nevertheless, both concepts achieved high retentions, with $\geq 96 \%$ for biochemical oxygen demand, $\geq 94 \%$ for chemical oxygen demand, and $\geq 99 \%$ for total phosphorus. Furthermore, the evaluation of both concepts showed that the specific electricity demand was 30\% lower than the average specific electricity demand for 105 traditional Swedish wastewater treatment plants with population sizes of 1500 - 10,000".

Another argument in favour of this simplified model is the fact that small WWTPs, not at least in Sweden, will have both considerable variations in incoming wastewater flows and loads. For these small plants, the owners have decided to operate them with only part-time attention at site. To what extent this perspective-to use only a well-controlled phosphorus removal at these smaller plants-will become a viable alternative to more conventional biological/chemical treatment models remains to be seen. Nevertheless, it is always important that critical questions such as the one presented by the thesis are raised, critically scrutinized and debated.

\section{Discussion on the Current Changes in Treatment Development}

The wastewater technologies have focused for a comparably long period on phosphorus removal in Sweden. On the other hand, the more recent demands on advanced removal of nitrogen, pharmaceutical remains and other complex compounds in the wastewater do not represent a typical Swedish contribution to the wastewater technologies. These fields, however, have represented new challenges to be solved within the municipal wastewater field. Typically, the basic import of various technologies had again to meet the Swedish conditions. Thus, a specific contribution is imperative for the successful wastewater treatment: How to meet the needs to treat cold wastewater. This matter concerns both biological, chemical and physical reaction rates that often are under-estimated when specific needs (technical solutions) are to be handled. In this perspective, it is interesting to widen the question by addressing the European Union's demand on effluents from municipal WWTPs, see "Council Directive 91/271/EEC Concerning Urban Waste Water Treatment" [1]. The directive has by large a less strict demand on the phosphorus discharge, compared with the normal Swedish demands. Another matter is the ongoing discussion on the nitrogen discharges, especially with respect to cold water treatment. This specific matter is not discussed further here. On the other hand, in the Swedish market the demands on phosphorus discharges were not at all less stringent for cold wastewater conditions.

An interesting field of development is currently what is labelled "Bio-P", meaning enhanced biological phosphorus removal. The model is by no means a 
novelty, as the early observations and studies are found already in the 1970s. Now, the matter is of central concern as a chemical savings model and a possible way to enhance biological treatment stability. In Sweden, some tests came about in the 1990s. One full-scale test focusing on low temperature wastewater was performed at a small WWTP in northern Sweden, see Marklund and Morling (1994) [4]. An interesting finding in the study was the temperature limitation on a successful enhanced biological removal, see Figure 5.

Even more, the long-term development of the phosphorus removal will include a recovery of phosphorus either directly from the wastewater or from the separated sludge stream.

Today many plants represent very low discharge levels with respect to P-concentrations. P-discharge levels from a few typical Swedish municipal WWTPs are shown in Table 1.

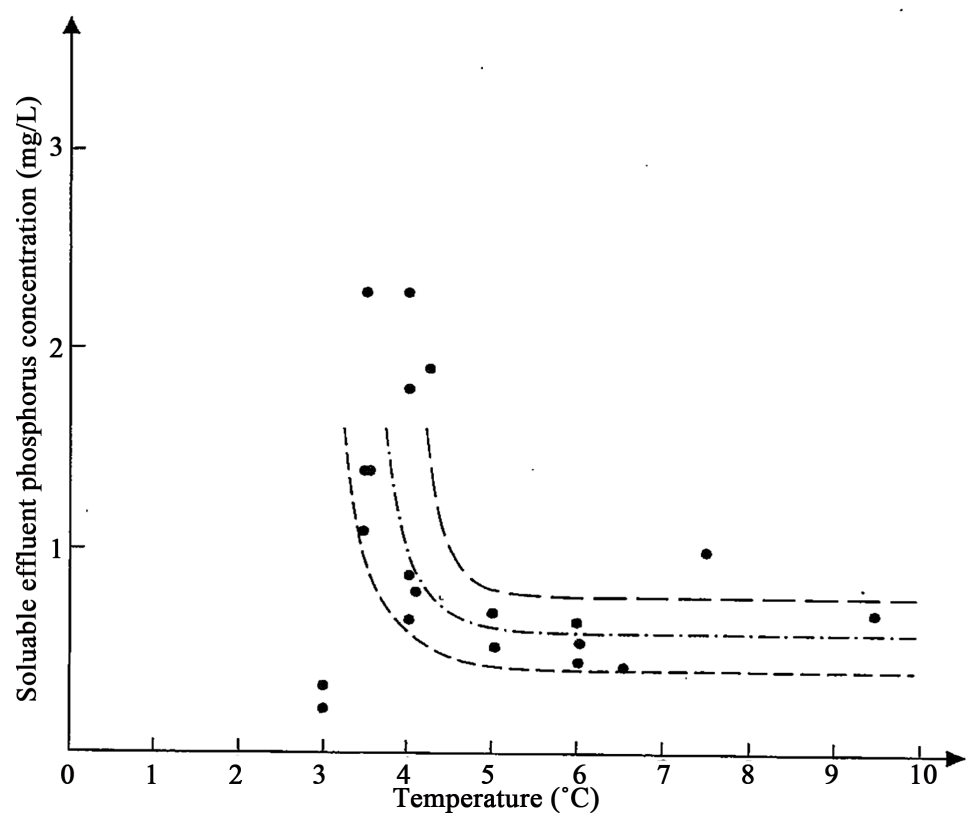

Figure 5. Outlet soluble phosphorus levels versus temperature (21 observations), see Marklund and Morling (1994) [2].

Table 1. Summary of discharge values from some Swedish municipal plants with respect to $\mathrm{P}$ (annual mean values).

\begin{tabular}{ccc}
\hline Plant name and size & Control year & Discharge level \\
\hline Klagshamn WWTP, Malmö 90,000 pe & 2014 & $0.20 \mathrm{mg} \mathrm{P} / 1$ \\
Duvbacken WWTP, Gävle 107,000 pe & 2015 & $0.27 \mathrm{mg} \mathrm{P} / 1$ \\
Torna Hällestad WWTP 800 pe & 2014 & $0.10 \mathrm{mg} \mathrm{P} / 1$ \\
Nynäshamn WWTP 25,000 pe & 2012 & $0.06 \mathrm{mg} \mathrm{P} / 1$ \\
Käppala WWTP 425,000 pe & 2014 & $0.20 \mathrm{mg} \mathrm{P/1}$ \\
Solviken WWTP, Mora 18,000 pe & 2015 & $0.14 \mathrm{mg} \mathrm{P} / 1$ \\
Ellinge WWTP, Eslöv 330,000 pe & 2014 & $0.19 \mathrm{mg} \mathrm{P/1}$ \\
\hline
\end{tabular}


Comments on the presented plants in the table with respect to the results:

1) All $P$ discharge values are annual values, based on many samples.

2) All plants, save for Torna Hällestad and Mora, include requirements on nitrogen removal as well. Typical discharge levels for all these plants are $<10 \mathrm{mg}$ total $\mathrm{N} / \mathrm{l}$ as annual values.

3) All discharge levels with respect to $\mathrm{BOD}_{7}$ are found to be in the range 3 to $10 \mathrm{mg} / \mathrm{l}$.

4) The Duvbacken WWTP is operated mainly with an enhanced biological phosphorus removal, and a minor polishing addition of alum to safeguard the stipulated effluent requirement of $<0.3 \mathrm{mg} \mathrm{P} / \mathrm{l}$.

5) The Ellinge plant treats a large amount of industrial wastewater, whereas the municipal contri-bution is $<30,000$ pe.

Two of these plants presented in Table 1 reflect typical examples of how the more complex environ-mental needs as identified throughout the years and met by a refined technology supported by the enhanced process knowledge.

\subsection{The Story from the Duvbacken WWTP}

A summary on the development in the phosphorus removal field may be given from the history of a large mid-Swedish wastewater treatment plant, serving the city of Gävle and sized for around 105,000-person equivalents. The plant was initially taken into operation in 1967, based on a "classic" activated sludge system, but no sludge stabilization. No specific phosphorus removal was included in this first stage.

Already after only 6 years of operation, the demand for phosphorus removal was raised. This resulted in the construction of a post-precipitation facility. A major investment was performed that in turn resulted in a P-removal of $>90 \%$, however, by the needed use of a rather high dosage of alum salt, typically 140 $\mathrm{g} / \mathrm{m}^{3}$.

After a few years of operation, a minor process modification was established by recycling the chemical sludge from the post-precipitation to the inlet part of the plant. Thus, the chemical used as a flocculation device accordingly established the P-removal in the primary treatment. This arrangement reduced the needed alum dose down to $110 \mathrm{~g} / \mathrm{m}^{3}$. This improvement inspired the operator to go further and introduce a pre-precipitation at the plant and use the post precipitation only as an "emergency polishing" stage. The gains in the chemical dosage were further established. The needed dose was now in the range of 90 $\mathrm{g} / \mathrm{m}^{3}$.

However, the possibilities were not "exhausted". For a long time, the precipitated sludge from the water treatment plant had been disposed in a 14-day interval to the sewer system. This in turn caused a "load shock" and thus operation problems at the Duvbacken WWTP in the same regularity. A decision was taken to build a controlled storage tank at the water treatment plant and install pumps and control devices. The operation was then changed. Pumping of a controlled, 
and smaller amount of precipitated sludge took place every night. The result in the plant was a further decrease in the added pre-precipitation agent, down to around $60 \mathrm{~g} / \mathrm{m}^{3}$.

The pre-precipitation mode also lowered the organic load on the activated sludge plant. This in turn made it possible to convert one fourth of the aeration tanks into anaerobic digesters for the sludge stabilization.

These actions of successive improvements were not enough. In the late 1990s the plant was upgraded to also use enhanced phosphorus removal. This process modification in turn resulted in a further decrease of the added precipitant, now used as a polishing device. In 2015 the needed addition of alum salt was only $10 \mathrm{~g} / \mathrm{m}^{3}$. This addition has by large been kept at this level during the coming years, see Ref. [5].

All these gained improvements may now be taken on board when the plant is to meet furthermore stringent effluent requirements. Not only this, the plant owner, the municipal water company, is now considering whether the future effluent water quality may pave the way for selling the treated wastewater as a raw water resource for certain industrial establishments in the area.

\subsection{The Story from the Nynäshamn WWTP}

The community of Nynäshamn, located some $65 \mathrm{~km}$ south of Stockholm, got its first WWTP in the mid-1970s. It was built as a so-called direct precipitation facility, including primary sedimentation, chemical injection, flocculation and final clarifiers.

About 20 years later, one of the first large wetland facilities was implemented, to handle both an upgraded phosphorus removal and a $70 \%$ removal of nitrogen. However, the chosen configuration did not meet the expected discharge qualities. After some consideration, the community resolved to include a biological stage, based on the SBR-technology. An additional reason for this decision was to get a stable nitrogen removal and to handle septic sludge from the surrounding areas. The decision was based inter alia on the very good performance results from a plant east of Stockholm, see Morling (2001). The plant performance was summarized in a paper, see Franquiz et al. (2014) [6], as follows: It should be underlined, that all the analysis results as quoted in the following are based on flow proportional 24 hour samples. The analysises have all been performed by accredited laboratories in Sweden.

- The ability to run the wetland throughout the year has been established since the introduction of the biological treatment stage.

- From many aspects, the wetland performed well after upgrading of the plant, providing discharge levels of $\mathrm{BOD}_{7}$ and the total $\mathrm{P}$ of very high quality. BOD-removal was most likely due to an oxidation of organic matters into $\mathrm{CO}_{2}$ and $\mathrm{H}_{2} \mathrm{O}$. This may be explained by a substantially lower organic load on the wetland; the BOD-concentration has decreased from about $30 \mathrm{mg} / \mathrm{l}$ to just above $10 \mathrm{mg} / \mathrm{l}$, and the discharge of BOD from the wetland is almost 
consistently less than $3 \mathrm{mg} / \mathrm{l}$.

- By combining the SBR with the wetland in a sequence it has been possible to operate the SBR with a very short cycle time, about $2.5 \mathrm{~h}$ compared to 4 to $6 \mathrm{~h}$ as a normal cycle time. The SBR-system is operated with a low F/M ratio, about $0.065 \mathrm{~kg}$ BOD $/ \mathrm{kg} \mathrm{SS} / \mathrm{d}$.

- The wetland has performed a very good nitrification and denitrification.

- The total P-concentration in the discharge has been decreased by about $50 \%$ from about 0.12 to $0.06 \mathrm{mg} / \mathrm{l}$ (annual average). The phosphorous removal in a wetland is normally a function of precipitation and absorption of solids. The long-term accumulation of $\mathrm{P}$ may become a problem, as the wetland will be saturated with respect to phosphorous. Other wetland operations have demonstrated that when the saturation level is reached, the discharge of phosphorous increases.

- The previously observed problem with odour from the inlet part of the wetland has disappeared.

- The need for chemical precipitant (alum salt) has been reduced by $50 \%$ as compared with previous operation.

In Figure 6 is presented the total flow scheme for the Nynäshamn plant. The annual nitrogen discharge is around $7 \mathrm{mg}$ total $\mathrm{N} / \mathrm{l}$.

The most significant result of the plant upgrade is illustrated by the decrease of the nitrogen discharge, as shown in Figure 7. The introduction of the upgraded system in 2004 has almost taken down the inlet concentration of nitrogen compared with earlier operation mode. As a result, the discharge nitrogen con-centration is ever since well below $10 \mathrm{mg} \mathrm{N} / \mathrm{l}$. The discharge levels with respect to total nitrogen and total phosphorus have been kept at the consistently low levels until 2016 with total $\mathrm{N}<10 \mathrm{ppm}$ and total $\mathrm{P}<0.1 \mathrm{ppm}$, see reference [7].

\subsection{Two Recent New Discharge Levels Adopted in Sweden}

Finally, two important examples from the Swedish context may add the understanding of the consistent improved demands on the effluent quality. For two major municipal WWTPs recently, during year 2017, new more stringent discharge requirements have been stipulated. These two plants serve the larger Stockholm area. The following discharge values have been set, see Table 2.

Table 2. Summary of new discharge consent values for two major Swedish municipal plants.

\begin{tabular}{ccc}
\hline Plant name and size & $\begin{array}{c}\text { Discharge level, } \\
\mathbf{N}(\mathrm{mg} \mathrm{N} / \mathbf{l})\end{array}$ & $\begin{array}{c}\text { Discharge level, } \\
\mathbf{P} \text { (mg P/l) }\end{array}$ \\
\hline $\begin{array}{c}\text { Henriksdal WWTP, Stockholm, } \\
1,600,000 \text { pe }\end{array}$ & $\begin{array}{c}\text { An annual mean value } \\
\text { of }<6 \mathrm{ppm}\end{array}$ & $\begin{array}{c}\text { An annual mean value } \\
\text { of }<0.2 \mathrm{ppm}\end{array}$ \\
$\begin{array}{c}\text { SYVAB WWTP, Stockholm } \\
\text { suburban area, } 400,000 \text { pe }\end{array}$ & $\begin{array}{c}\text { An annual mean value } \\
\text { of }<6 \mathrm{ppm}\end{array}$ & $\begin{array}{c}\text { An annual mean value } \\
\text { of }<0.2 \text { ppm }\end{array}$ \\
\hline
\end{tabular}




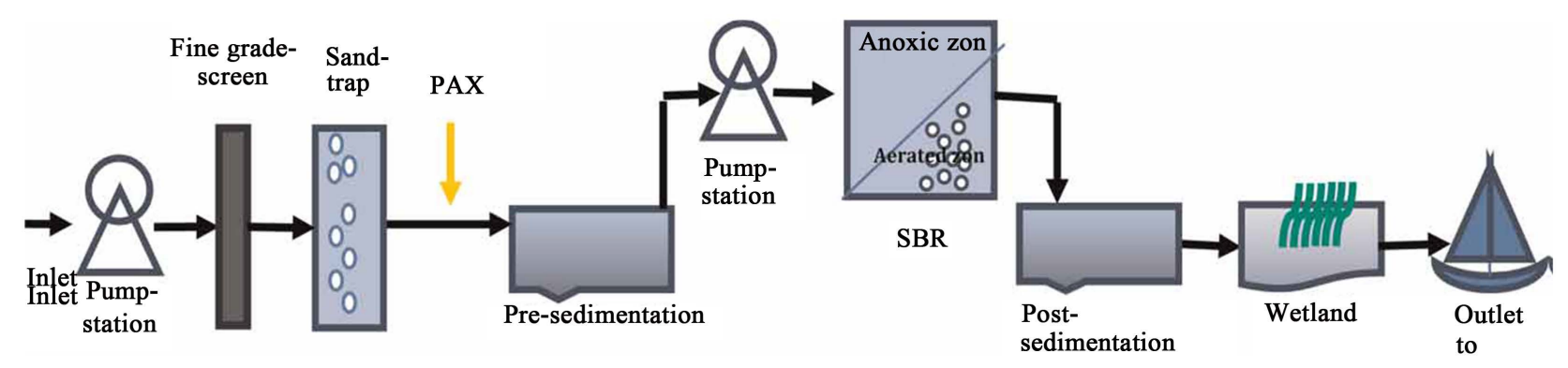

Figure 6. A simplified treatment train for the Nynäshamn WWTP.

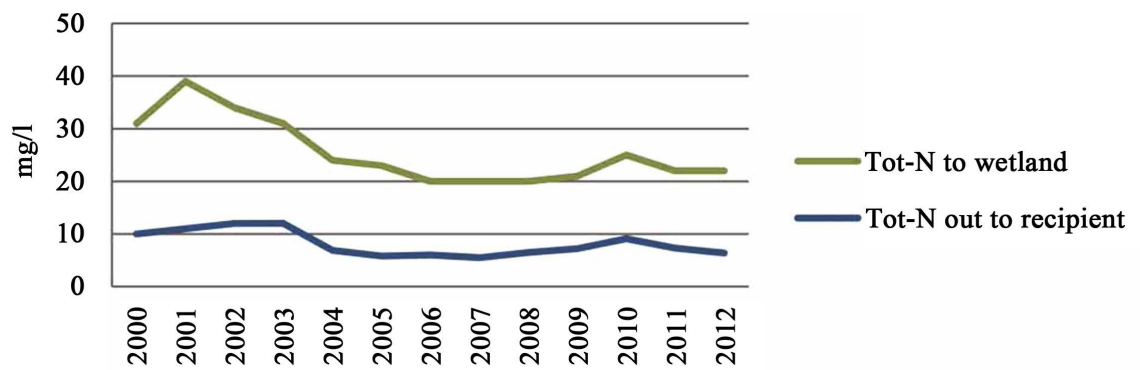

Figure 7. Inlet and outlet nitrogen concentrations to the wetland stage at the Nynäshamn WWTP.

Comments: The needed statistical definitions for these mean values are not included in the permit. These further definitions will be given by the local authorities that are responsible for the continuous control of the operation. The annual consent values will also include the wastewater volumes that have been by-passed the main treatment facilities. These sharpened criteria are now introduced for most new legal consent requirements in Sweden for larger municipal WWTPs.

\section{Conclusions}

The Swedish contribution to the international water technology may be rather modest, mainly reflected by the simple fact that a small country has limited resources. However, a specific field, such as the chemical phosphorus removal has been an exception to this statement. By questioning a more or less "administrative" attitude, stipulating that only a post-precipitation model would be accepted, a variation of methods and process combinations became a paradigm. The experiences from this 50 year development may be summarized as follows:

- The development has allowed an ongoing process refining. This is both reflected in more stable discharge levels and improved operation economy;

- The occurrence of competing technologies within the field has become an important improvement of the temporary knowledge within the water environment protection field;

- The deepened insights in actual process opportunities have also developed the different models to combine the chemical precipitation with other process stages within the treatment plants; 
- The growing interest in enhanced biological phosphorus removal represents additional improvements to further improve the operation efficiency, see for instance the case of Duvbacken WWTP;

- The recent focus on phosphorus as a limited resource will further focus on the recovery of phosphate from municipal sludge and even more stringent effluent requirements;

- The story of phosphorus removal illustrates the needs for a continuous ongoing research and development within the water environment field. This attitude has been defined by one of few internationally well-known Swedish academics, Professor H.S. Nyberg, a true humanist, whose field was Oriental Languages. He once stated the following with respect to true scientific work:

"The Scientific history is a never-ending auditing protocol. The scientific work will always be a never-ending revision of hypothesis and scientific viewpoints. The matters that bring about the progress are the mistakes and false assumptions. These deeds are, as a matter of fact, the needs and challenges for the next generation to restart some of the work. Quite a lot of what our generation has regarded as undisputed truths will in perhaps only 50 years time be superstitious viewpoint, without little or any value. For us it may be enough to have acted as eye-opener and outlined the pathway".

\section{Acknowledgements}

Anders Finnson, Swedish Water and Wastewater Association, Per-Lennart Karlsson M. Sc. Mathematics, Carl-Olof Zetterman, CEO for the SYVAB WWTP in southern Stockholm suburban communities have all contributed with added viewpoints to the text. Mr Pär Håkan Bergström former CEO at Cerlic Controls $\mathrm{AB}$ has assisted in specific corrections by undertaking a time consuming scrutinization work, thank you. Sophie Taintor at Sweco Environment AB has scrutinized the text from linguistic viewpoints and adjusted mistakes. Thank you all for the contribution to this paper.

\section{Conflicts of Interest}

The author declares no conflicts of interest regarding the publication of this paper.

\section{References}

[1] European Union (1991) Council Directive 91/271/EEC Concerning Urban Waste Water Treatment.

[2] Morling, S. (2001) "Performance of an SBR-Plant for Advanced Nutrient Removal, Using Septic Sludge as a Car-Bon Source. Water, Science and Technology, 43, 131-138. https://doi.org/10.2166/wst.2001.0128

[3] Hey, T. (2016) Municipal Wastewater Treatment by Microsieving, Microfiltration and Forward Osmosis: Concepts and Potentials. LTH, Water and Environmental Engineering, Department of Chemical Engineering, Faculty of Engineering, Lund University, Lund. 
[4] Marklund, S. and Morling, S. (1994) Biological Phosphorus Removal at Temperatures from 3 to $10^{\circ} \mathrm{C}-\mathrm{A}$ Full Scale Study of a Sequencing Batch Reactor Unit. Canadian Journal of Civil Engineering, 21, 81-88. https://doi.org/10.1139/194-008

[5] Community of Gävle (2017) Annual Environmental Report for the Duvbacken WWTP. (In Swedish)

[6] Franquiz, A. Morling, S., Måhlgren, J. and Westlund, Å. (2014) Long Term Experiences of Sequencing Batch Reactor-System and Wetland Treatment from a $\mathrm{Mu}$ nicipal Wastewater Treatment Plant in Sweden, Operated with Low Temperature Wastewater. Water Practice \& Technology, 9, 235.

[7] Community of Nynäshamn (2016) Annual Environmental Report for the Nynäshamn Central WWTP. (In Swedish) 